\title{
Foster Youths' Views of Adoption and Permanency
}

\section{Kate Chambers, Erica H. Zielewski, and Karin Malm}

A $s$ of September 30,2005, 513,000 children were in the foster care system. A significant portion (40 percent) of hese children were teens. During this year, 5,750 children age 13 or older were adopted from the foster care system. To contrast, nearly 25,000 youth were emancipated from the foster care system this same year (U.S. Department of Health and Human Services 2006). Child welfare officials report few families are interested in adopting older youth, and many caseworkers do not actively seek adoptive placements for teens because the youth are unsure or hesitant about being adopted (Geen, Malm, and Katz 2004). At the same time, prior research conducted with adolescents who have been adopted shows that adopted foster youth are generally happy they have been adopted (Wright and Flynn 2006).

In 2007, Urban Institute researchers conducted five focus groups with a total of 34 foster youth age 11 through 19 in New York City and Washington, D.C., over several months. The teen participants were living in various placement settings - kin and nonkin foster homes and group homes. When surveyed, nearly all of them had a permanency goal of independent living. In the focus groups, the teens were asked about permanency, adoption, and recruitment activities. The focus groups evolved from our earlier work on recruitment and retention of adoptive parents in which we heard from child welfare caseworkers that older youth were not always interested in adoption and often refused to participate in recruitment activities; yet, we had not previously talked directly with youth. This brief presents information from the 2007 focus groups to provide insights into foster youths' perceptions of permanency, adoption, and recruitment.

\section{What Is Permanency?}

The term "permanency" in the foster care system has many definitions. Legally, "permanency" means a family-based permanent living status, such as reunification, guardianship, or adoption, while others believe that long-term foster care is also "permanent" (Freundlich et al. 2005). When asked what permanency means to them, many youth in our focus groups referred to permanency as a physical or concrete entity, such as "staying in one place" or "a place to stay until you age out [of the system]." Some youth noted that long-term foster care can be a permanent placement, but were careful to point out that foster parents could still have foster youth removed from the home. Other youth suggested that permanency was less about a physical location and more about a "commitment" from people. For example, one youth likened permanency to a permanent marker, "if you [draw] on the paper, the mark ain't going nowhere. The paper may go somewhere or it could be picked up, but the mark ain't going nowhere." When asked about the permanency options available to them, many youth were aware of the different options, which they noted included adoption, guardianship, reunification, independent living, and "aging out" of the system.

\section{How Do Youth Participate in Permanency Planning?}

Youth were asked about their experience with different permanency options. The majority of the youth in the focus groups had a goal of reunification at one time during their case. Many of them believed that being reunified was the "best option" and should be the "first option" for children taken out of their homes. Yet, the youth openly discussed why they were never reunified with their family, often citing their parents' inability to comply with the case plan.

While many youth had plans to reunify with their biological families at one time, approximately half of them noted that their caseworkers had discussed adoption as a permanency option, typically around age 13 to 15 . Yet, as a result of those discussions, only a small proportion of youth actually had adoption as a permanency goal.

Reasons adoption did not remain youths' permanent goal included their concerns about being adopted, feeling like they were "too old" to be adopted, and their desire to enter an independent living program. Another barrier raised by several youth was their parents' reluctance to give up parental rights. One youth described his parents' mentality as "if I can't have you, no one else will." Another youth stated that his caseworker was not even able to discuss adoption with his mother because "every time she heard that word [adoption], she didn't like it because she felt like I was being taken away from her." 
"If you [draw] on

the paper, the

mark ain't going

nowhere. The paper

may go somewhere

or it could be picked

up, but the mark

ain't going nowhere."
One youth suggested that the reason adoption is not discussed with many foster children is because it is only a real option for those children who do not actively see their parents; for most foster children, their parents are still involved.

Youth were also asked how their permanency goals were established. One consistent theme among all the youth was their belief that they had significant influence over deciding their permanency goal, with one youth stating that she could change her goal "at any time." However, many youth conceded that their caseworkers first raised the subject. Several youth also identified their lawyers, the court, and their families as affecting their permanency goal decisions. While the majority of youth said their caseworker began discussing a change in their permanency goal when they were around 14 to 15 years old and that they themselves were able to influence this decision, some youth stated that they only had the legal right to make decisions influencing their permanency goal at 16. In both New York and D.C., the age that older children are required to give consent to their adoption is 14 (Child Welfare Information Gateway 2007). Although the youth agreed that they should have the ability to make decisions about their permanency goal at any age, they were also concerned about whether all youth were mature enough to make a decision that was in their best interest.

\section{What Do Youth Think about Older Child Adoption?}

Many youth stated that their caseworkers had discussed adoption with them at some point during their case. Yet, at the time of our focus groups, most of them had a goal of independent living. We asked youth what they thought about older children being adopted, in part to explain the majority who experienced a change in permanency goal to independent living. The youth had very strong opinions about older child adoption. Most thought that they were too old for adoption, while others in the group had concerns about being adopted and thought that aging out of the system was a more appropriate option.

The general consensus among the youth, however, was that no one wants to adopt teenagers. What was less clear was how they arrived at this judgment. Some youth suggested that people think teenagers in the foster care system are "bad" or that there must be "something wrong with them" if they have been in multiple placements. Another youth suggested that the media portrayed youth in a negative light, such as "doing drugs and stealing cars," which may deter prospective families from wanting to adopt teenagers. The youth felt that people would rather adopt younger children for multiple reasons, including this perception that all teenagers in the foster care system are "bad." Several youth talked about teenagers being "set in their ways" and expressed that "everyone [adults] thinks your mind is closed and that you're not going to listen." This idea seemed to resonate with the youth, as another youth stated that people want to adopt younger children because they have time to teach them about life: "They've got time to build memories with them."

At the same time, the youth in the focus groups discussed reasons teenagers may have concerns about being adopted. For instance, some youth indicated that teenagers were concerned about being adopted because most had been in the foster care system for a long time, which led them to feel that no one wanted them or that something must be wrong with them. One youth added that "most teenagers don't understand it's not their fault [that they are in the system for a long time]." Another youth likened it to the problems many foster youth face in finding stable foster care placements, reasoning that if foster parents are unwilling to take foster youth into their homes, then "why would they even want to adopt them?" Additionally, most youth agreed that teens would be "picky" about their adoptive placements, with one youth saying, "They stereotype us [youth] and we stereotype them [adoptive parents]."

The youth also shared their views on how life would change if they were adopted. These perceptions seemed to come from their experiences with friends who have been adopted, as well as their experiences in various foster homes. For example, most youth said that they lost almost all contact with friends and siblings who have been adopted, noting it was like they "disappeared." Some youth stated that their friends' and siblings' adoptive parents prohibited contact because they felt that the foster youth were bad influences or feared that their adopted child would leave them. Or, for many youth, their lost contact with siblings and friends occurred because they moved out of the 
Youth are concerned about being "stuck" and looked at as a "closed case" if they enter an adoptive placement.

While nearly half the youth had adoption

as a permanency

goal, only a small

proportion had

experience with

recruitment

activities. area or changed schools. Yet, for youth who were in stable foster care placements, they believed that life for them would probably not change much if they were adopted. Few youth voiced a positive perception of adoption, though one youth who did stated that he would "probably have more better days than worse days." He felt that he would have more freedom than he currently has as part of the child welfare system. Others in the group disagreed with this perspective and felt that they had more freedom in a group home or foster home because they can leave their placement if they do not like it. In an adoptive home, they reasoned, you are "stuck."

\section{What Do Foster Youth Fear about Adoption?}

The youth shared several prevailing concerns about being adopted, including the notion that once you are adopted you are "stuck." This negative connotation, as opposed to the positive aspects of finding a "permanent family," seemingly relates to the problems that most youth said they had experienced in foster homes. For example, many youth were concerned that if adopted, the system would view them as a "closed-case," meaning that they would not be able to leave an adoptive placement they do not like. Others were concerned about the uncertainty that comes from a new type of placement. As one youth stated, "I don't know what I'm going to get [with adoption]." She felt that she knew what to expect with independent living and that she had some power and control over her living situation.

This fear of what would happen if they were adopted seemed to be a common perception among the teenagers. Many were concerned and even stated they were "afraid" of not knowing what to expect from an adoptive placement. Others viewed adoption more cynically, stating that the adoptive parents will begin by "being nice to your face," but as in their experience in foster homes, will change once the adoption is finalized. One youth said that one reason for this is because some adoptive parents adopt children for the wrong reasons, such as making themselves "look good" to the public. She continued that, "Some people think if they are like 'I adopted this child and it's not mine,' that they get put up for some sort of glory."
Another shared, yet not surprising, concern among the youth was that they would lose contact with their friends and family if they were adopted, much like they had lost contact with friends and siblings in the past. They were concerned that they would have to leave their communities or schools if they were adopted. Finally, some youth were concerned about the benefits that they receive as a foster youth and, in their view, may lose as an adopted youth. One youth stated that you "get more out of the system from being in foster care," like school fees and a clothing allowance.

\section{What Do Youth Think about Participating in Adoption Recruitment Activities?}

When asked about adoption recruitment, the youth were extremely candid in pointing out that they rarely see the community try to find homes for foster youth in America. They noted that they often see advertisements asking people to help children in Africa and other countries but strongly felt that people need to "look at the kids here." The youth, however, were able to identify several adoption recruitment activities, including matching events or parties (events where prospective adoptive families meet and interact with children available for adoption), 'Speaker's Bureaus' (a public event where foster youth talk about the importance of adoption), 'Wednesday's Child' (a short weekly news segment featuring a child or sibling group waiting to be adopted), and radio advertisements.

Despite nearly half the youth in focus groups having had adoption as a permanency goal at some point during their case, only a small proportion of them had had any experience with adoption recruitment activities. A few youth had participated in a matching event, while others had directly experienced or knew of someone who had experienced media-based recruitment (such as television segments, photo galleries, or radio advertisements). The youth who had participated in recruitment activities started participating in these events between ages 13 and 15. Unfortunately, these youth did not express positive experiences with recruitment. For instance, one youth shared her experience at a match event, noting that at first, she did not know what the purpose of the event was. Once potential adoptive parents started 


\section{Three important}

\section{findings:}

- Foster care experiences influence adoption perspectives

- Youth have

concerns and fears about adoption

- Youth expect autonomy and want to feel empowered asking her questions about being adopted and event staff asked her to fill out forms, however, she realized that she was participating in a recruitment event and asked not to be involved because she did not want to be adopted at the time.

A few youth in the focus groups had been asked to participate in media-based recruitment, with only one accepting. The youth who participated said that she went to a studio and filmed the segment but it was never aired. Another youth stated two of his sisters had been involved with media-based recruitment and that they "liked" the experience. Another youth who declined to be involved in media-based recruitment said he did not want to be adopted at the time. When asked whether they would like to participate in mediabased recruitment, all the youth who had not had the chance to participate said that they would not. When asked why, most said that the experience would be "embarrassing" because "all your friends would look at you and know you had no place to go." The youth felt that this would be particularly hard for a youth who had not told anyone that he or she was in foster care. Another youth added, "You don't want no one to feel sorry for you, because it's hard enough that we have to be in the system, hard enough that we have to be a statistic." Interestingly, while most youth stated that they would not want to be recruited for using media, many of them said that using the media was still a "good thing" for those children who want to participate.

Although many youth were wary of older child adoption, several youth suggested that for teenagers to be adopted, the foster youth should speak with the prospective parents first because they believed foster youth were "running our own lives anyway." One youth involved with recruitment activities stated that letting the foster child speak conveys a positive image of foster youth and lets foster youth know they are wanted and can be adopted.

\section{Implications and Discussion}

Though exploratory, the information provided by older foster youth raises three important findings:

1. Foster care experiences influence adoption perspectives. Foster youths' perceptions of adoption and permanency appear informed by their experiences living in foster homes and the lack of continued communication and involvement with their friends and siblings who have been adopted. Subsequently, it also appears that the negative connotations most teenagers have toward adoption affect their perception of and willingness to participate in adoption recruitment activities.

2. Youth have concerns and fears about adoption. The foster youth expressed feelings of uncertainty about being placed in an adoptive home and the degree of power they perceive they would give up if they were to move to a "closed case" adoptive placement. Some of their key concerns were not knowing what to expect from an adoptive placement, being "stuck" in an incompatible adoptive home, losing contact with friends and family, and leaving their community.

3. Youth expect autonomy and want to feel empowered. A recurring theme throughout our discussions with youth was their sense of control over their permanency goals, their placements, and, ultimately, their lives. Foster youth appear to have learned to expect and accept a high level of autonomy (for example, a perceived large role in deciding their permanency goal) and, like all children, covet stability. Being adopted, to the youth, is perceived as giving up some of their power and would mean entering a placement they do not know much about, as well as the possibility of losing stable elements in their lives, such as their friends, the school they attend, and the city where they live.

Our findings indicate that child welfare agencies and caseworkers have more to do in educating youth about adoption and other permanency options. Youths' perceptions of adoption are clearly shaped by their experiences in foster care and through the validity in their friends' and siblings' adoption experiences. The youth we spoke with had many real concerns about adoption, such as losing autonomy and having less control, being separated from friends and family, and the possibility that the adoptive placement may disrupt. It is also important to look at youths' fears in the context of their development into adulthood. All teenagers want a large degree of autonomy, not just foster youth. Have foster youth begun to expect a higher level of independence than nonfoster youth, and because of this, when should caseworkers 
"Let us kids speak

\section{with the parents, have us have the} voice." intervene and override some of their decisions? Professionals may need to acknowledge the youths' concerns directly and help them cope through different preparation methods (i.e., therapy, open adoptions that allow youth to continue connections with biological family) if agencies want to increase adoption among older foster youth.

\section{References}

Child Welfare Information Gateway. 2007. "Consent to Adoption: State Statutes Series." http://www. childwelfare.gov/systemwide/laws_policies/statutes/ consent.cfm\#_noteref5. (Accessed November 12, 2007.)

Freundlich, Madelyn, Rosemary Jane Avery, Sara Munson, and Sarah Gerstenzang. 2006. "The Meaning of Permanency in Child Welfare: Multiple Stakeholder Perspectives." Children and Youth Services Review 28(7): 741-60.
Geen, Rob, Karin Malm, and Jeff Katz. 2004. "A Study to Inform the Recruitment and Retention of General Applicant Adoptive Parents." Adoption Quarterly 7(4): 1-28.

U.S. Department of Health and Human Services. Administration on Children, Youth and Families, Children's Bureau. 2006. "Preliminary FY 2005 Estimates as of September 2006 (13).” http://www. acf.hhs.gov/programs/cb/stats_research/afcars/tar/ report $13 . \mathrm{htm}$.

Wright, Lois, and Cynthia C. Flynn. 2006.

"Adolescent adoption: Success despite challenges." Children and Youth Services Review 28(5): 487-510.

\section{Acknowledgments}

The authors would like to acknowledge the guidance of Jennifer Macomber and Rob Geen. This study was supported by a grant from the Freddie Mac Foundation. 


\begin{tabular}{|l|l|} 
THE URBAN INSTITUTE \\
2100 M Street, NW \\
Washington, DC 20037
\end{tabular}$\quad \begin{gathered}\text { Nonprofit Org. } \\
\text { U.S. Postage } \\
\text { PAID } \\
\text { Permit No. 8098 } \\
\text { Easton, MD }\end{gathered}$

Address Service Requested

THE URBAN INSTITUTE

2100 M Street, NW

Washington, DC 20037

Copyright $\odot 2008$

Phone: $202-833-7200$

Fax: 202-467-5775

Web: http://www.urban.org

To order additional printed copies of this publication, call 202-261-5687 or visit the UI online bookstore, http://www.uipress.org.
The child welfare research program brief series monitors how child welfare policy becomes practice, identifies important emerging issues in child welfare research, and summarizes findings from practical studies to help inform the public policy debate.
The views expressed are those of the authors and do not necessarily reflect those of the Urban Institute, its board, its sponsors, or other authors in this series. Permission is granted for reproduction of this document, with attribution to the Urban Institute. 